\title{
Implementing Peer Assessment in a Russian University ESP Classroom
}

\author{
Olga Stognieva \\ National Research University Higher School of Economics \\ Correspondence concerning this article should be addressed to Olga Stognieva, National Research \\ University Higher School of Economics, Kirpichnaya, 33, Moscow, Russian Federation, 115187. \\ E-mail:2507794@mail.ru
}

\begin{abstract}
In order to develop the skills and competences required in a professional environment, university students have to reflect on their own role in the learning process. The traditional methods of assessment do not assess reflective thinking, critical thinking, self-evaluation and peer evaluation. Peer assessment may be a way to solve this problem. In this paper, it is researched how peer assessment could be applied to higher education and the effect of using this form of assessment on the quality of learning. The methodology to investigate the effect of peer assessment as a part of the learning process includes literature observation, case study, developing protocols and marking criteria rules for peer assessment, examples of peer assessment strategies and activities. The results of the research demonstrate that peer assessment methods of either written or oral performance can trigger a deeper involvement of students both in the learning and in the assessment process, keep motivation up and develop some qualities essential for future professional life. Therefor peer assessment could be effectively integrated in the course of ESP at the Moscow Higher School of Economics.
\end{abstract}

Keywords: peer assessment strategies, marking criteria, evaluation methods, reflective practice

The main goal of professional higher education is to help students to become reflective practitioners who are able to critically evaluate their own professional practice (Schon, 1983; Falchikov, 2002; Davies, 2006). Students in real-life situations must be able to analyse information, apply their problem-solving skills and communication abilities, and to reflect on their own role in the learning process.

The traditional methods of testing in ESP classroom do not fit such goals as reflective thinking, critical thinking, self and peer evaluation (Dochy, Segers, \& Sluijsmans, 1999). Assessment procedures should not only serve as a way to monitor the students' progress but also to reflect the tasks that students will encounter in the world beyond university. Therefore, the interest in alternative assessment practices is increasing globally. At the English Language Department for Economic and Mathematical Disciplines in the Higher School of Economics (HSE) in Moscow, Russia, there is a demand for time effective assessment techniques for evaluating the students studying English for Specific Purposes (ESP) at the faculty of Business Informatics. Interaction is a common feature of communication in everyday and professional lives and this needs to be reflected in the assessment procedures, or at least taken into consideration.

\section{Materials and Methods}

\section{Research Questions}

In this paper, the author argues that peer assessment can be effectively integrated in the teaching-learning process and bring significant benefits to students such as an improvement in their ability to direct their own learning, and their own performances and to become interdependent members of the professional and scholarly communities, which according to Schon (1983) emphasizes, the central role that peers play in providing structured opportunities for discussion and reflection.

It addresses the following research questions:

a) How could peer assessment be applied to ESP courses in HSE?

b) What is the effect of using this form of assessment on the quality of oral and written performance? 
The rest of the paper has been organised in the following way: first, the theoretical grounding for peer assessment will be reviewed. Second, guidelines, rules and marking criteria for peer assessment will be presented and some examples of peer assessment strategies used at the Higher School of Economics will be provided. Third, the case study will be described, which verifies the effectiveness of peer assessment in teaching English for Specific Purposes (ESP). The final section outlines the results of the study and makes suggestions for future educational practices in Russian universities.

\section{Definition of Peer Assessment}

This paper uses two mutually helpful definitions of peer assessments. First, Falchikov defines peer assessment as 'the process whereby groups of individuals rate their peers, who are students of equal status to one another' (Falchikov, 1995, p. 176). This process may or may not entail previous discussion or agreement over criteria. It may involve the use of rating instruments or checklists, which have been designed by others, before the peer assessment exercise, or they be designed by the user group to meet their particular needs. Second, peer assessment has also been suggested to be a way of evaluating the quality or success of either a person or a product by others (Topping et al., 2000). Therefore, peer assessment feeds self-assessment activities particularly through the cycle of receiving and giving feedback.

Students often undertake peer assessment in conjunction with formal self-assessment at university. They reflect on their own efforts, and enrich this reflection by exchanging feedback on their own and their peers' work.

Peer assessment can be a powerful meta-cognitive tool. Rogers (1969, p. 104) emphasises that 'we cannot teach another person directly; we can only facilitate their learning.' A person learns mostly only those things, which they are involved in. Peer assessment engages students in the learning process and develops their capacity to reflect on and critically evaluate their own learning and skill development. It supports the development of critical thinking, interpersonal and other skills, as well as enhancing understanding within the field of knowledge of a discipline. Peer and group assessment are also often undertaken at the same time. Normally, as in a business environment, the members of a group assess the performance of their peers in terms of their contribution to the group's overall work.

\section{Benefits of Peer Assessment}

Peer assessment is a powerful tool that contributes significantly to the learning process. The most important advantage of self-assessment and peer assessment is that it makes students realise that 'success or failure depends not on innate talent, luck or ability, but on practice, effort and using the right strategies. This is motivating and empowering' (Petty, 2009, p. 275).

Peer assessment has the following benefits:

- it engages students in the learning process and develops their ability to reflect on and evaluate their own learning and development of skills (Race, 2001)

- it can foster levels of responsibility among students for they must be fair and accurate with the judgement they make regarding their peers (Keaten \& Richardson, 1993)

- it can develop reflective learners who take responsibility for their learning and develop lifelong learning skills (White, 2011)

- it helps to integrate knowledge and better understand required standards (Hanrahan \& Isaacs, 2001)

- when structured marking schemes are used, peer assessment has an acceptably high level of validity and reliability (Sadler \& Good, 2006)

- it can increase confidence (Topping et al., 2000)

- it encourages students to participate actively in tutorial activities (Divaharan \& Atputhasamy, 2003)

- it can reduce the lecturer's assessment workload (Hernandez, 2010)

- with formalised peer assessment processes, students can become more active agents in assessment procedures. 'Students thus feel the ownership of the assessment (and learning) process rather than alienated or victimised by it' (Nulty, 2009, p. 3)

Despite the fact that many researchers have recognized peer assessment as a valuable tool for assessment and learning in education, it is underestimated in HSE. Peer assessment is not normal practice and peer assessment strategies are not widely applied in teaching practices at HSE (Zhavoronkova, 2014, p. 143). This paper is aimed at suggesting the ways of peer assessment strategies can be effectively integrated in the curriculum of the ESP courses at the Moscow Higher School of Economics.

This study on peer assessment was conducted at the Moscow Higher School of Economics, while teaching the Preparation for IELTS course to 24-second year students (aged 19-20) from the faculty of Business Informatics. The second year students were selected because they are likely to be searching for permanent work after university, and the skills presented in the intervention would be helpful for them to learn for their future workplace. As the students initially were not familiar with any peer assessment rules and procedures, at the pre-research stage it was 
essential to explain them how it could be effectively assimilated in the learning process. That enables students to better understand assessment rules and procedures, and work towards improving their own performance.

\section{Developing Guidelines and Rules for Peer Assessment}

For peer assessment to be effective in the classroom, it is important that students are made aware of the rules for giving feedback to their peers. This will help to create a learning environment based on trust and mutual respect. The teacher may wish to involve students in the process of creating the rules or devise the teacher's own set of rules. The teacher may offer the students to think of five rules that they believe are important for effective peer assessment and make them into a list. Then the students should compare their lists with a partner's and decide which suggestions are the best five from the two lists. The responses can then be used to develop a list of ground rules, which can be displayed in classrooms. A sample of peer feedback guidelines, as displayed in Figure 1, might be used as support to conduct the procedure of peer assessment if students have never done it before.

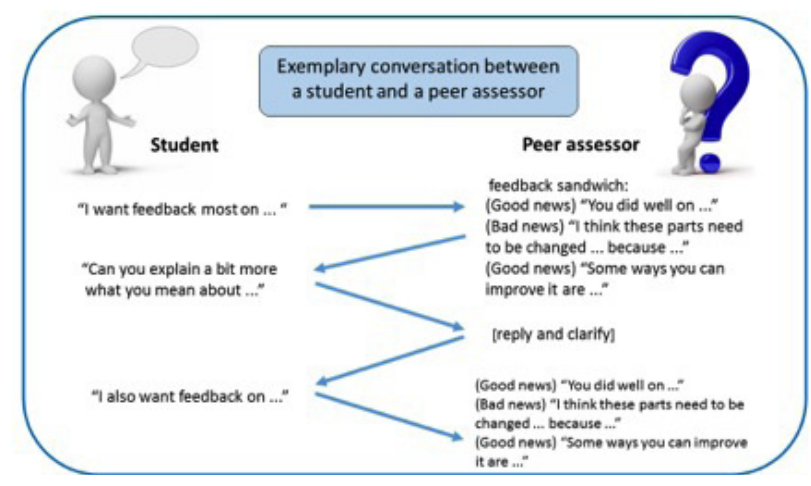

Figure 1. Sample of peer feedback guidelines.

\section{Examples of Peer Assessment Strategies Used in ESP Classes}

In this section, some examples of peer assessment strategies, which are divided into three levels of difficulty, will be described. The activities mentioned in this section are adapted from White (2011), implemented in ESP classes at the Higher School of Economics for they are new for Russian ESP classes, and allow achieving the goals of this research. As peer assessment skills could be developed in the process of systematical tuition, all the activities have been practiced before the main part of the research was conducted in order to allow the students to acquire some peer assessment skills. It was designed to teach them three levels of peer assessment strategies and to contribute to the development of reflective thinking and deeper involvement of students both in the learning and in the assessment process.

In case the student has never encountered peer assessment strategies before, more simple tasks can be offered, like Feedback strips, PMI or Spoof assessment.

Feedback Strips: these are useful for oral presentations or demonstrations. They can be short and simple and more than one peer can provide the feedback. The name of the person being observed is written on the strip and the observer completes the prompts.

\section{Name:}

Today you did well on ...

One thing you could work on improving is ...

Next time you could try ...

PMI: this is another tool that can be used to help students to evaluate a piece of writing or presentation, which is a 'pluses, minuses and interesting' way of evaluating. It encourages students to look at the strengths and weaknesses of the presentation and to think about the evidence for their decisions.

\begin{tabular}{l}
\hline \multicolumn{1}{c}{ PLUS / MINUS / INTERESTING } \\
\hline $\mathrm{P}(+)$ plus \\
\hline $\mathrm{M}(-)$ minus \\
\hline $\mathrm{I}(?)$ Interesting
\end{tabular}

Figure 2. PMI.

Spoof Assessment is a fun activity, which is used to teach students how to spot mistakes and correct them. It familiarises them with the marking criteria and prepares them for evaluating their own and others' work. The teacher pairs the students together and gives them a spoof piece of writing with some common errors to begin with. Students work on their own to find what is wrong with it, why it is wrong and how to do it correctly. Each student then explains the errors in their spoof work to their partner, followed by a discussion of why it is wrong.

Since students have been aware of the rules for giving feedback to their peers, they might be offered such activities as Graphing progress, Snowballing, The group marking its members.

Graphing Student Progress is an activity that should be done at regular intervals. The teacher asks students to chart their progress and learning. The graph could be constructed using data from class work, test results, 
assessment marks or mini class quizzes. Students can then share their charts with the class, in small groups or in pairs. Students may give each other reasons and suggestions as to how they have improved and what goals they wish to achieve next. This task allows students to share their successes with each other, but also allows students to learn from one another through helpful suggestions and advice.

Snowballing is an activity that involves students collaborating to produce a group answer. They are organised into small groups and are given questions to answer, which they initially work on individually. Students then compare their answers, reasoning and methods. They discuss them and try to agree on the best answers and decide why they chose that response.

The group marking its members is one of the possible processes for formally assessing group work. The teacher assigns a mark to each group, then for students to assign an individual mark to each member of their group, based on the contribution they perceive each to have made to the group's work. A major contributor would receive a mark higher than the group mark and a lesser contributor would receive a lower mark. An average for each student can be generated from the range of marks their peers give them (Brown et al., 1997, p. 175).

At a more advanced level of development of peer assessment skills, students can be offered the Testing learning, Peer composition or Built in back-feedback strategies to follow.

Testing Learning is a pair or small group work to create the students' own questions or tests with a marking scale. The tests can then be shared with other students. Once completed the creators can mark the test and give feedback on how responses could be improved. A number of online sites, including Google docs, can be used by students to create multiple choice quizzes. Smart notebooks also have various interactive activities that can be used to assess learning, including multiple choice questions. A fun version of this is to get students to create a board game where they have to answer questions correctly to move forward. Alternatively, students can create flashcards to test their partner's knowledge.

Built in back-feedback. This activity is adapted from Assessment Toolkit of the University of New South Wales Australia (2015). In this activity, the teacher should give an active role to students being assessed by letting them respond to the assessment. For example, students engaged in an extended writing task anonymously exchange work for feedback on a few occasions during the drafting process. Rather than grading each other's work, each student assesses their peer's performance as a reviewer, and this contributes to the final grade of the student doing the peer reviewing. The teacher assesses the quality of feedback given, and this contributes to the group mark of the feedback-providers.

Peer composition. This activity (Ghaith, 2014) enables students to assist each other in generating ideas for writing and incorporating peer feedback in order to improve their written work. Firstly, students work individually on their topics, then they are joined into pairs and discuss their plans, taking notes of developed ideas. After that, they write the first paragraph of each composition together, making sure that they have a good start on their compositions (they finish the writing individually). Finally, the students proofread their partner's composition and make suggestions for better writing patterns.

\section{Case Study}

To explore the effect of peer assessment as a part of the learning process, a case study was conducted among the students, followed by a questionnaire.

The main framework of the methodology was originally inspired by Harvey (2015), but modified for the intervention in Russia.

Firstly, the students were offered to write a descriptive essay following the IELTS Writing Task 1, spending about 20 minutes on this task.

Here is a sample of the task: 'The bar chart at Figure 3 shows the percentage of students who passed their high school competency exams, by subject and gender, during the period 2010-2011. Summarise the information by selecting and reporting the main features, and make comparisons where relevant. Write at least 150 words' (the task is taken from http://www. ielts-exam.net).

At the second stage, the students were divided into small groups of six. In small groups, they were asked to develop marking criteria to use in peer assessing for a particular task and discuss them in general discussion, which took place between all the groups. As Race (2001) outlines, a staged in-class process for developing criteria encourages student engagement and a sense of ownership.

Marking criteria help students to decide whether their peers have achieved the goals of the task or not (White, 2011).

A successful marking criteria includes the following aspects:

- be limited in number so students are not overwhelmed by the scope of the task

- be supported, where necessary, by samples which make their meaning clear

- created with input from students so that they have greater understanding and ownership.

Table 1 indicates the criteria developed in the general discussion and accepted for peer assessment 


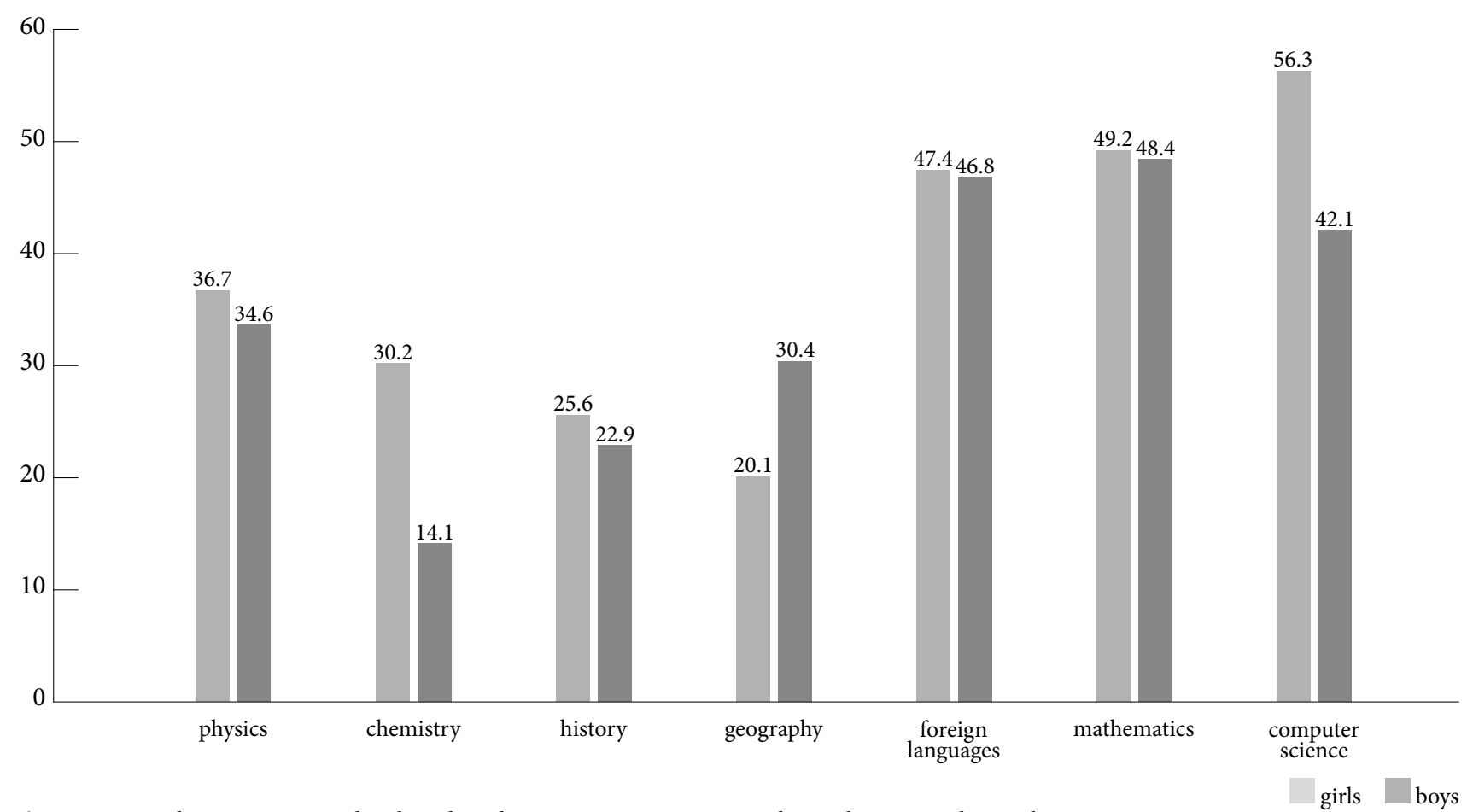

Figure 3. Students passing high school competency exams, by subject and gender, 2010-2011.

Table 1

The criteria developed during the general discussion

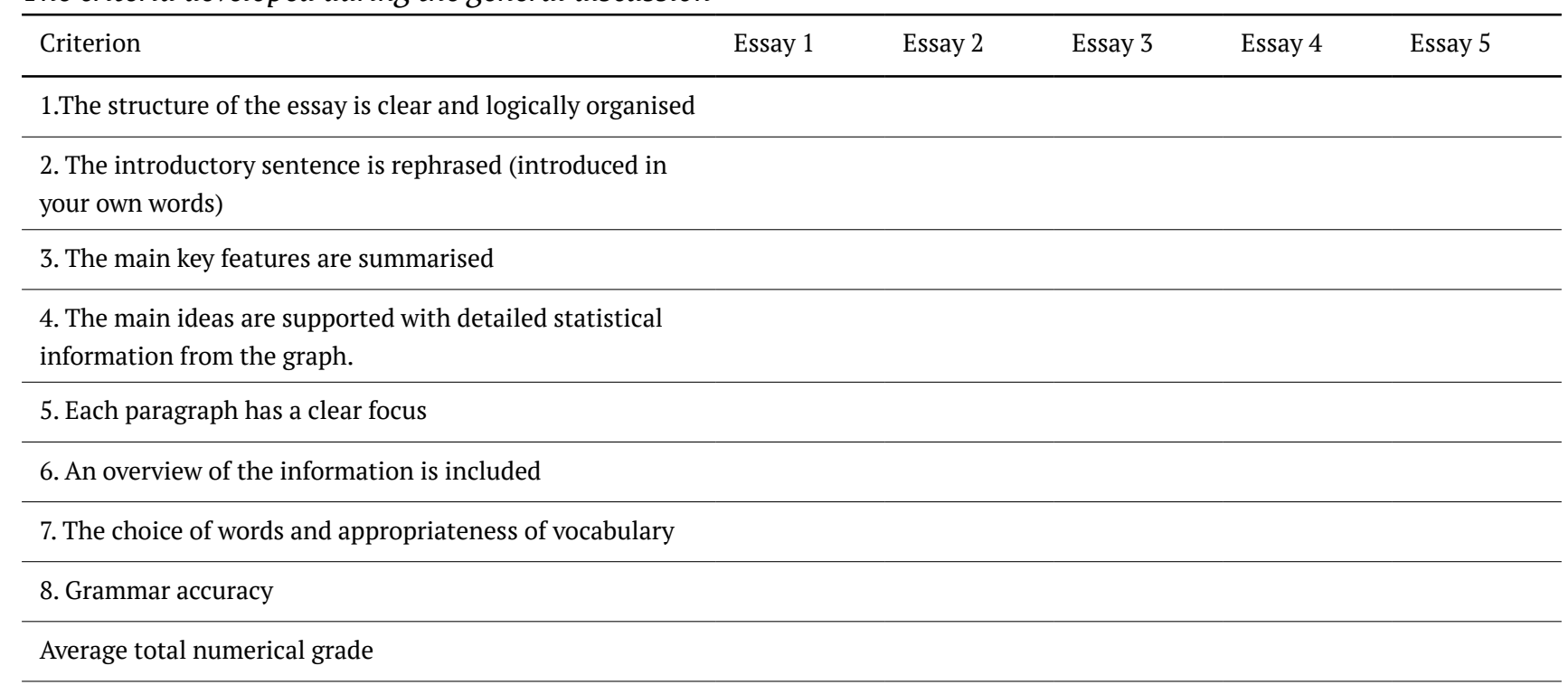

of the essay. The choice of criteria was driven by the requirements for IELTS writing part 1.

The differentiation between the various levels of achievement was also discussed, first in small groups and then in general discussion between the groups and presented in Table 2.

Once the students constructed the criteria, they assessed five essays written by their peers according to the criteria they discussed. They assessed each criterion according to the scale $1,2,3 \ldots . .10$ with 4 as the lowest pass mark. This enables an average total numerical mark to be awarded, based on the overall criteria. The students were allowed to refer to IELTS Task 1 Writing band descriptors (public version) for more information.

At the fourth stage, the students provided more extended feedback in an oral form, based on how well the criteria are supported by evidence, as well as the style and presentation of the data and give feedback to assign a positive or negative judgment for each essay. 
Table 2

Differentiation between the various levels of achievement

\begin{tabular}{llllll}
\hline $\begin{array}{l}\text { Level of } \\
\text { achievement }\end{array}$ & Limited (E) & Just passed (D) & $\begin{array}{l}\text { Quite satisfactory } \\
\text { (C) }\end{array}$ & $\begin{array}{l}\text { Highly satisfactory } \\
\text { (B) }\end{array}$ & Outstanding (A) \\
\hline Grades & $1-2-3$ & $4-5$ & $6-7$ & $8-9$ & 10 \\
\hline $\begin{array}{l}\text { A brief } \\
\text { description } \\
\text { of the level of } \\
\text { achievement }\end{array}$ & $\begin{array}{l}\text { unrelated to the } \\
\text { task }\end{array}$ & $\begin{array}{l}\text { generally addresses the } \\
\text { task; the format may be } \\
\text { inappropriate in places }\end{array}$ & $\begin{array}{l}\text { addresses the } \\
\text { requirements of } \\
\text { the task }\end{array}$ & $\begin{array}{l}\text { covers all } \\
\text { requirements } \\
\text { of the task } \\
\text { sufficiently }\end{array}$ & $\begin{array}{l}\text { fully satisfies all } \\
\text { the requirements }\end{array}$ \\
\hline
\end{tabular}

After peer assessment the students were able to make changes in their assignment if they found their peers' advice valuable.

At the final stage, the teacher analysed all the feedback given and made some adjustments that they considered necessary.

Following their assignment, the students were asked to fill in a questionnaire, which provided information for further analysis.

They were asked the following questions:

1. How did you feel about being assessed by your group-mates?

2. Did you find that assessment made by your group mates was fair?

3. What did you gain from this activity?

\section{Results}

Figure 4 shows student ratings in response to questions about their feelings while being assessed by their peers. The majority of the students $(84 \%)$ evaluated the experience of being assessed by their peers positively; $16 \%$ were less positive about peer assessment, they either disagreed (8\%) or strongly disagreed (8\%).

$75 \%$ of students claimed that the feedback they received was constructive and helpful, $13 \%$ remained neutral. The remaining $12 \%$ of students either disagreed (8\%) or strongly disagreed (4\%) in response to this statement.

About $70 \%$ of the students felt that their assessment of their peers was accurate. They also pointed out that peer assessment is a good method and fair. In general, Figure 5 demonstrates that there was a high level of agreement between the grades given by peers and those given by the teacher.

Figure 6 shows the students' rating in response to three additional questions concerning the qualities, which were developed in the peer review process.

Almost three quarters of the students (71\%) pointed out that they developed better skills in assessing other students' essays, because they applied the criteria multiple times, and this process helped them better understand the requirements of the task and became more confident in assessing their peers.

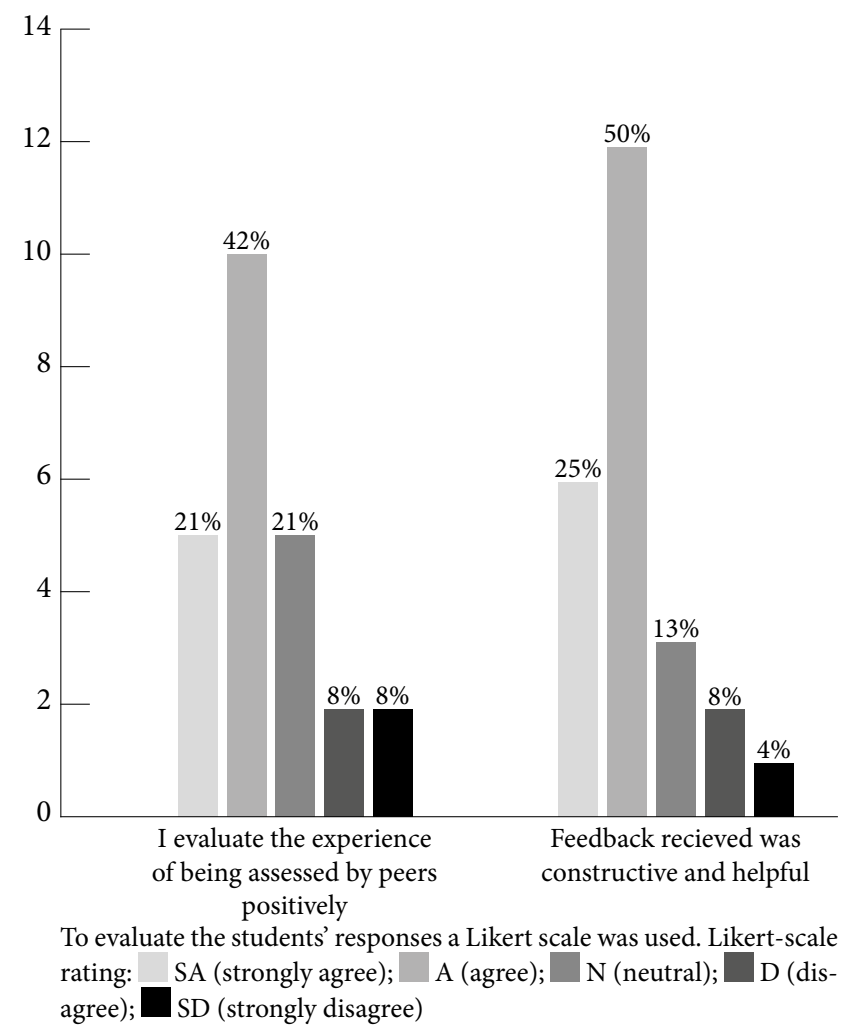

Figure 4. The students' answers on how they feel about being assessed by their peers.

$75 \%$ of the students agreed that the collaborative development of criteria before the task helped them not only to better understand and remember the structure and other components of the essay, but also allowed them to learn a lot about their own work through analysing others. This demonstrates that their learning behaviour became more reflective.

$83 \%$ of the students agreed that the quality of the task improved in the results of the peer assessment in terms of the developed criteria, and they found that the advice given at the stage of the extended feedback, based on how well criteria are supported by evidence, 


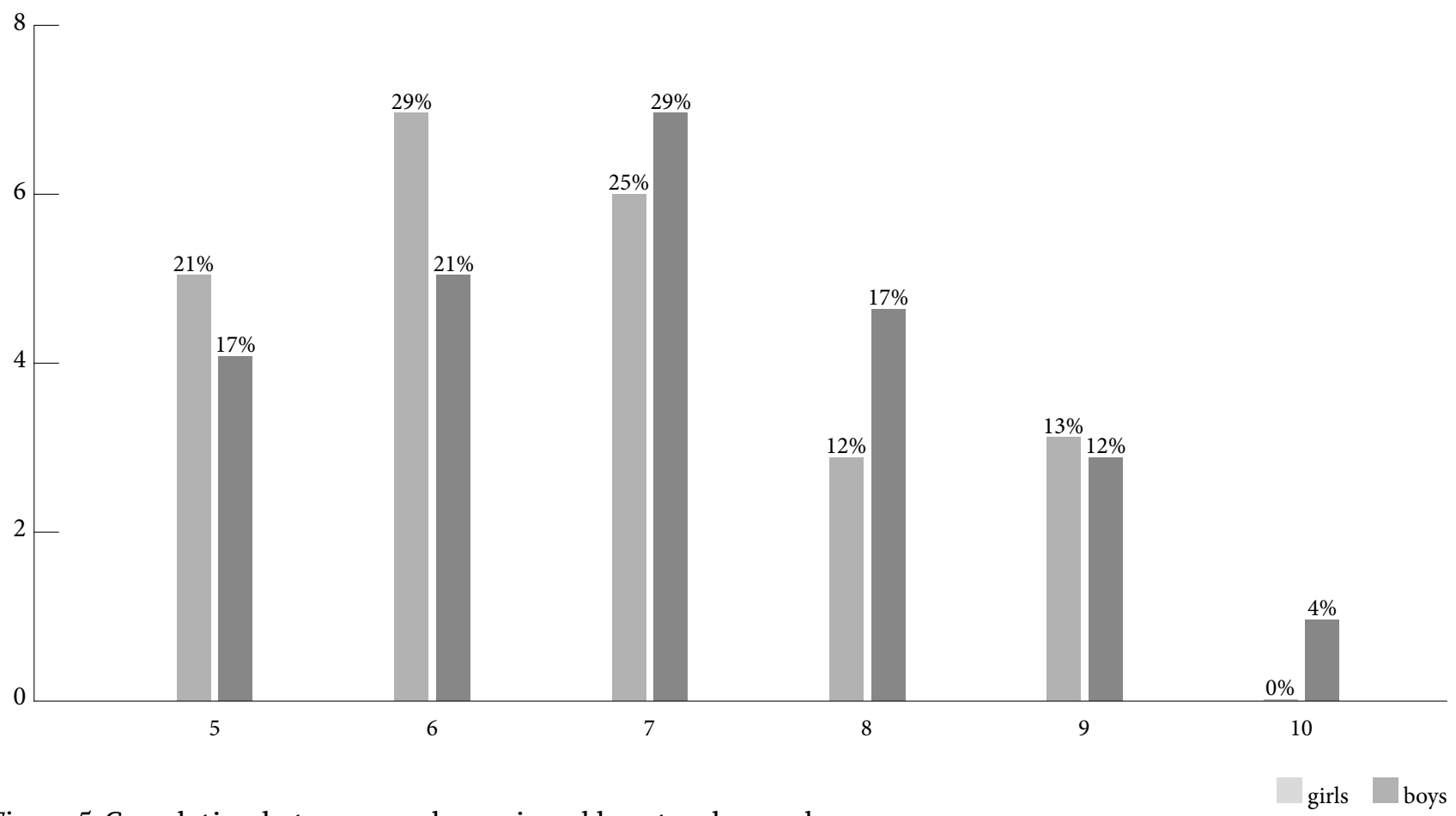

Figure 5. Correlation between grades assigned by a teacher and peers.

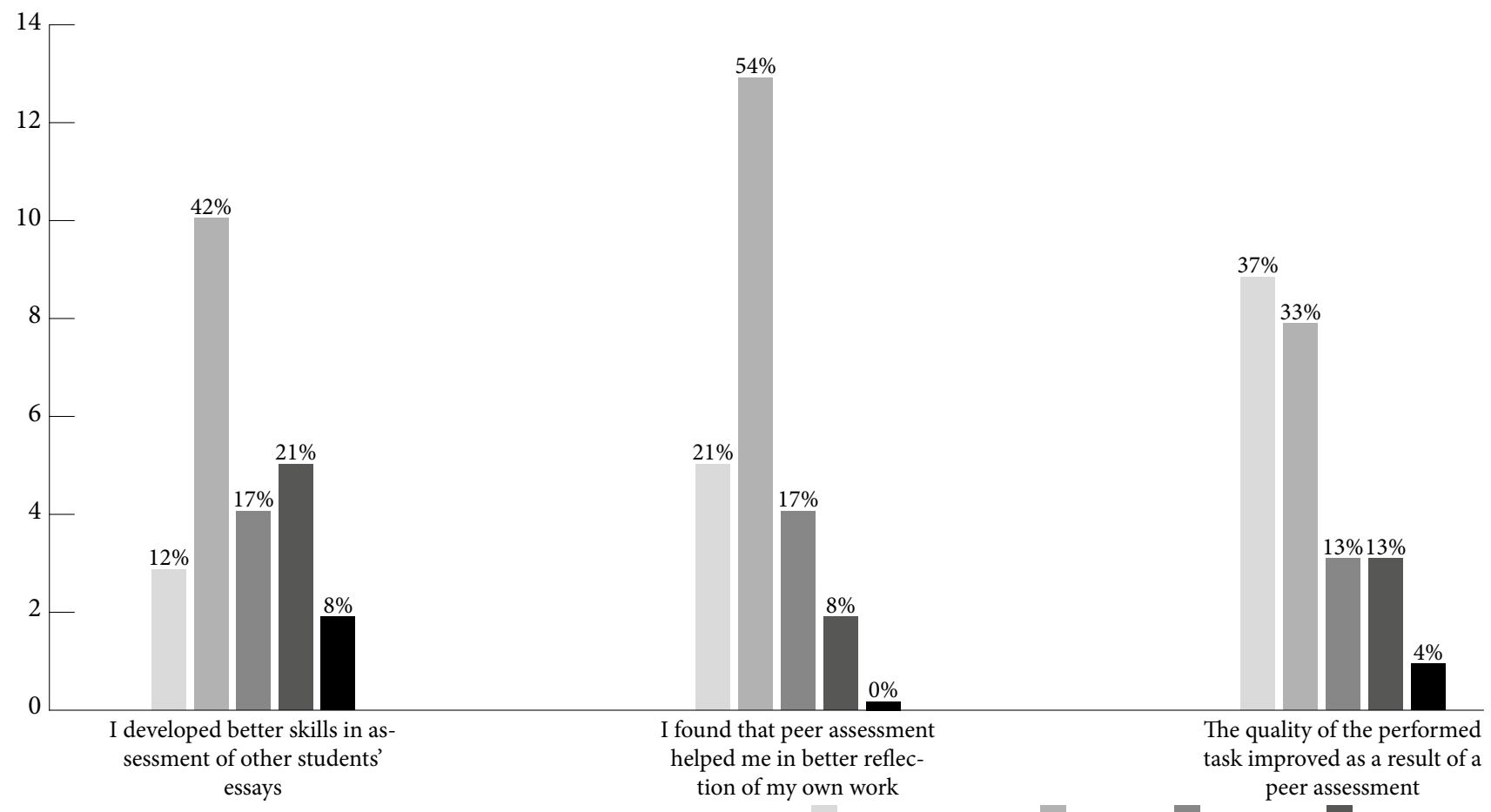

To evaluate the students' responses a Likert scale was used. Likert-scale rating: $\quad$ SA (strongly agree); $\square$ A (agree); $\square$ N (neutral); $\square$ D (disagree); SD (strongly disagree)

Figure 6. The students' answers on what they gained from peer assessment activity.

was very useful. They had improved in confidence and organisation of material. They displayed higher overall performances and significantly better attitudes to the peer assessment process than those students who were not engaged this way. With this exercise, students can reflect on their work early in an assessment process.

For better understanding of the changes and improvements made in the process of peer assessment, 
an example of pre-peer assessment piece of writing (Essay 1) and after-peer assessment version (Essay 2) is provided.

\section{Essay 1}

The bar chart gives information about the results of students who passed their high school competency exams from 2010 to 2011.

It can be notice from the graph that girls and boys got the same results in Foreign Languages and Mathematics. Half of all male and female students passed these two subjects. History is the exam which girls and boys did not good in as the results were worse than in other subjects, with $25.6 \%$ of girls and $22.9 \%$ of boys passing. Male and female students differ in success in Chemistry, Geography and Computer Science. Girls attained a passing rate of $30.2 \%$ in Chemistry, when only $14.1 \%$ of boys passed $i t$. We can see from the bar chart that female attained a passing rate of approximately $56 \%$ in Computer Science but the figure for boys is about $42.1 \%$.

The results of boys in Geography was 10.3\% higher that the result of girls because only $20.1 \%$ of girls were succeed on the exam.

In conclusion, both genders were not bad in Mathematics and Foreign languages as their results were quiet similar, but equally poor results in History. Boys have better results in Geography, whereas girls have better results in Chemistry and Computer Science.

\section{Essay 2}

The following bar chart illustrates the results of boys and girls who were successful in their high school competency exams in the period from 2010 to 2011, by subject.

Firstly, it can be seen from the graph that both girls and boys attained similar rates in Foreign Languages and Mathematics. About half of all male and female students passed those two subjects.

On the other hand, both genders performed almost equally poorly in History, with $25.6 \%$ of girls and $22.9 \%$ of boys passing.

Male and female students differed in their success in Chemistry, Geography, and Computer Science. Girls attained a passing rate of just over $30 \%$ in Chemistry, whereas only $14.1 \%$ of boys passed that course. In addition, female students also did better than boys in Computer Science; over 55\% of girls passed the Computer Science competency exam, but only $42.1 \%$ percent male students passed the test. Almost a third of all boys passed the Geography exam, whereas just over one-fifth of girls made a passing grade.

In conclusion, both male and female students did equally well in Foreign Languages and Mathematics, but did equally poorly in History. Boys got better grades than girls in Geography, whereas girls had better passing rates in Chemistry and Computer Science.

After peer assessment intervention, some significant changes in the student's essay could be observed, for example, the changes in the choice of words, the structure of the essay, paragraphing, summarizing the key features, improvements in the use of grammar. All the changes were made according to the criteria, which have been introduced before the writing activity and in the focus of peer assessment procedure.

The level of the student's achievement significantly increased in the process of peer assessment as shown in the examples. For the original piece of writing (prepeer assessment essay), the student attained 5 points out of 10 . His essay generally addressed the task but the format, vocabulary and grammar were inappropriate in places. The after-peer assessment version fulfilled all requirements of the task sufficiently, so the student attained 9 points out of 10 . This example demonstrates a positive effect of peer assessment as a part of the learning process.

\section{Discussion}

The peer assessment intervention revealed that it could be a valuable instrument for students to improve the development of their critical abilities. The results of the case study demonstrate that of a sample group of students who followed this process, $80 \%$ reported it to be useful, and the majority stated that they started work on the assignment earlier than they would have otherwise. The students claimed that after their work had been assessed by their peers, they incorporated elements of the peer feedback into their essay. Students became more motivated and more involved in the learning and assessment process. They found the peer assessment to be sufficiently fair and accurate.

The findings of the study reported in this paper indicate four main benefits that the students participating in the peer review gained.

First, the feedback that students received from their peers was mainly constructive and helpful to them. Assessment in higher education should prepare students for making complex judgements about their own work and the work of others (Boud \& Falchikov, 2004). This is a useful skill to learn whilst still at university, as these students will be faced with similar situations in their future workplaces, where they will have to work together in teams and support one another, whilst giving continuous feedback on performance levels.

Second, the students' self-assessment and critical assessment of other people improved, which helped them to gain a better personal evaluation of their work. 
As Keaton et al. (1992) reported, peer assessment is a practice that can foster high levels of responsibility among students; the students must be fair and accurate with the judgments they make regarding their peers. Peer assessment also helped them to refine their approach to criticising other people and to frame their critique in a constructive way that would not invite animosity amongst their peers. It is also important that students learn how to self-analyse and have a more objective stance on their own work, as well as being receptive to changes that their peers or seniors might make to their work.

Third, it was noted that the students became more engaged with their learning and tried to avoid mistakes, as they were aware that they were being assessed and were eager to achieve good marks. Moreover, given that the students had the opportunity to observe one another's work and determine the quality of it, this may have inspired them to work harder, and become more competitive to attain better grades. Clarke, Timperley \& Hattie (2003) emphasised that as students work to meet their own goals, they are much more focused and achieve success more quickly. This success builds their confidence and they are then much more willing to attempt more challenging targets. Due to the fact that the intervention was conducted in five stages, where the students' work was evaluated and discussed by 5 other students and constantly improved, the end quality of the students' essay was of a very high standard. Although this long process is not a realistic reproduction of a work cycle in a business, the aim of the exercise was to help the students practice their criticism to create a good resultant product (essay). The high standard of the essays after the criticisms was because the students had many opportunities to improve their work and discuss it with others.

Fourth, the intervention may have increased the cohesion between the class and the teacher, as the students had to work together and interact with the teacher (as an expert reviewer) as they evaluated each other's work. With the introduction of peer assessment the role of the teacher is evolving into a partnership with students to help them learn how to critically evaluate their own learning and thinking. Darling-Hammond (2005) indicated that self-critique can increase students' responsibility for their own learning and make the relationship between teacher and student more collaborative. Peer assessment helps in this endeavor.

The original general hypothesis stated that peer assessment methods of either written or oral performance could trigger a deeper involvement of students both in the learning and in the assessment process, keep motivation up and develop some qualities essential for future professional life. Thus, the intervention has found some evidence to support the hypothesis and contributes to an analysis of the peer assessment approach in teaching ESP in Russia. However, it should be noted that these peer assessment strategies are an effective learning tool only if they are properly and consistently used in a series of lessons over time, so that the students can become used to the process and understand their place in this process.

\section{Limitations}

There are potential limitations in this study, which could affect the interpretation of the data. The sample size is quite small $(n=24)$ as the author of the research was working alone and it was not possible to find other teachers who were prepared to use the intervention. The sample size should be expanded by engaging other teachers who are ready to implement these peer assessment strategies as a part of their everyday practices for obtaining better results in teaching a foreign language. We are exploring these possibilities with our colleagues in the Higher School of Economics and data for larger sample sizes may be available as a result of this study in future. Therefore, this study does contribute to the growing database on peer review assessments in Russia.

There are two further limitations to the assessment process that the author attempted to account for in the research. First, as Falchikov (2003) noted, is that initially implementing the peer assessment may result in some resistance from students. This may be due to shyness and an unwillingness to criticise their friends, or a more general impression of the assessment as not useful or relevant to their future careers and practical skills. However, the initial resistance from the class was overcome by explaining the benefits to be gained from participating in the assessment process, carefully planning our activities and involving students in discussions about potential problems that we anticipated before they arose. The criteria against which achievement is to be judged should be clear and unambiguous. These may help to change students' attitudes and encourage them to participate positively in the exercise. Second, the reliability of the peer assessment results may be questioned, as some may say that the students are not qualified to mark other students' work. However, Falchikov and Goldfinch's (2000) research demonstrated that peer assessment can be as reliable as that of lecturers and lead to a higher degree of student motivation. Our research also demonstrated that there was a high level of agreement between the grades given by peers and those given by the teacher. 


\section{Conclusion}

In this paper, it is researched how peer assessment could be applied to higher education and the effect of using this form of assessment on the quality of learning. The author proposes a methodology to investigate the effect of peer assessment as a part of the learning process, while teaching the Preparation for IELTS course to the students from the faculty of Business Informatics at the Moscow Higher School of Economics. More specifically, the deliberate and systematic use of peer assessment practices through all levels of study help students to develop an understanding and appreciation of the judgments which other qualified professional peers would make of their work and which they learn to make of those peers and themselves. Peer assessment can be effectively integrated in the teaching-learning process and brings some benefits to students such as an improvement in their ability to direct their own learning and performances, be critical and evaluate oneself and other people.

Although the results presented here have demonstrated the efficiency of peer assessment strategies, it could be further developed in a number of ways. Peer assessment being a valuable tool for university education is not widely used in practice, so the future work should be in implementing the peer assessment strategies in the curriculum of the English Language Department for Economic and Mathematical Disciplines. The way in which these proposed strategies could be effectively integrated in future courses is through the introduction of a combination of self-assessment and peer assessment strategies for written or oral assignments, for this combination fosters reflection on the learning process. Secondly, it might be worthwhile to selectively repeat the study in the other faculties of the Higher School of Economics, but before that, it should be well adapted and modified to the needs of teachers and students, being supplied with descriptive instruction on the procedure for intervention.

\section{References}

Boud, D., \& Falchikov, N. (2004). Beyond formative and summative assessment: Developing a new agenda for assessment for lifelong learning. In 2nd Biannual Joint Northumbria/EARLI SIG Assessment Conference. Bergen, Norway: University of Bergen.

British Council (2012). IELTS Guide for teachers. Retrieved from http://www.britishcouncil.it/sites/ britishcouncil.it/files/ielts_guide_for_teachers_ italy.pdf

Brown, G., Bull, J., \& Pendlebury, M. (1997). Assessing student learning in higher education. London, UK: Routledge.

Clarke, S., Timperley, H., \& Hattie, J. (2003). Unlocking formative assessment: Practical strategies for enhancing students' learning in the primary and intermediate classroom. Auckland, New Zealand: Hodder Moa Beckett.

Darling-Hammond, L., \& Bransford, J. (Eds.). (2005). Preparing teachers for a changing world: What teachers should learn and be able to do. San Francisco, CA: Jossey-Bass.

Davies, P. (2006). Peer assessment: Judging the quality of students' work by comments rather than marks. Innovations in Education and Teaching International, $4(1), 69-82$.

Divaharan, S., \& Atputhasamy, L. (2003). Influence of peer assessment on the quality of cooperative learning: A pilot study. REACT, 22(2), 103-113.

Dochy, F., Segers, M., \& Sluijsmans, D. (1999). The use of self-, peer- and co-assessment in higher education. Studies in Higher Education, 24(3), 331350.

Falchikov, N. (1994). Learning from peer feedback marking: Student and teacher perspectives. In H. C. Foot, C. J. Howe, A. Anderson, A. K. Tolmie \& D. A. Warden (Eds.), Group and interactive learning (pp. 411-416). Southampton, UK: Computational Mechanics Publications.

Falchikov, N. (1995). Peer feedback marking: Developing peer assessment. Innovations in Education and Training International, 32(2), 175187.

Falchikov, N. (2003). Involving students in assessment. Psychology Learning and Teaching, 3(2), 102-108.

Falchikov, N., \& Goldfinch, J. (2000). Student peer assessment in higher education: A meta-analysis comparing peer and teacher marks. Review of Educational Research, 70(3), 287-323.

Ghaith, G. (2002). Using cooperative learning to facilitate alternative assessment. English Teaching Forum, 40(3). Retrieved from http://americanenglish.state.gov/ resources/english-teaching-forum-2002-volume-40number-3

Hanrahan, S. J., \& Isaacs, G. (2001). Assessing selfand peer-assessment: The students' views. Higher Education Research and Development, 20(1), 53-70.

Harvey, J. (n.d.). Signpost 10: How am I doing? Using peer reviews to improve assignments. Retrieved from https://www.northumbria.ac.uk/static/5007/ arpdf/cetlpdf/signpost10.pdf

Hernandez, R. (2010). Benefits and challenges of using self and peer assessment UCD teaching and learning/ resources. Retrieved from http://www.ucd.ie/t4cms/ UCDTLA0033.pdf 
IELTS-Exam.net. (2014). IELTS Writing Task 1 \#123. Retrieved from http://www.ielts-exam.net/ academic_writing_samples_task_1/874/,\%202015

Keaten, J. A., \& Richardson, M. E. (1992). A field investigation of peer assessment as a part of the student group grading process. Paper presented at the Western Speech Communication Association Convention, Albuquerque, NM.

Nulty, D. (2008). A guide to peer and self-assessment approaches and practice strategies for academics. Brisbane, Australia: Griffith Institute for Higher Education, Griffith University. Retrieved from http://www.griffith.edu.au/_data/assets/pdf_ file/0016/142108/GuidePeerSelfAssessment-Long. pdf

Petty, G. (2009). Evidence-Based teaching: A practical approach. Cheltenham, UK: Nelson Thornes Ltd.

Pond, K., UlHaq, R., \& Wade, W. (1995). Peer review: A precursor to peer assessment. Innovations in Education and Training International, 32(4), 314323.

Race, P. (2001). A briefing document on self, peer and group assessment. Retrieved from www.ltsn.ac.uk/ genericcentre

Rogers, C. R. (1969). Freedom to learn: A view of what education might become. Columbus, $\mathrm{OH}$ : Charles E. Merrill.

Sadler, P., \& Good, E. (2006). The impact of self- and peer-grading on student learning. Educational Assessment 11(1), 1-31.

Schön, D. (1983). The reflective practitioner. How professionals think in action. New York, NY: Basic Books.

Topping, K., Smith, E., Swanson, I., \& Elliot, A. (2000). Formative peer assessment of academic writing between postgraduate students. Assessment and Evaluation in Higher Education, 25(2) 150-169.

UNSW. (2015). Assessment toolkit: Student peer assessment. Retrieved from https://teaching.unsw. edu.au/printpdf/544

White, L. (2011). Self-Assessment and peer-assessment. A leaflet on supporting independent learning. Retrieved from http://assessmentfeedbackreportin gfolio.weebly.com/uploads/4/0/2/8/40283179/selfassessment_and_peer_assessment.pdf

Zhavoronkova, A. R. (2014). Self-Assessment and peer feedback as useful practices in efficient foreign language acquisition. The National Association of Scientists, Monthly Scientific Journal, 5(1), 143-147. 